\title{
Reforma y rehabilitación del Café Dindurra de Gijón
}

\author{
Antonio Fernández Morán \\ Arquitecto
}

\begin{abstract}
RESUMEN
El análisis arquitectónico y su base histórica fueron claves para establecer tanto el criterio argumental como el alcance de la actuación desarrollada. El contacto de Manuel del Busto con una de las obras más singulares de Hans Poelzig, el Grosses Schauspielhaus (Berlín,1919) se constituye como inequívoco referente de su actuación en el Dindurra (1930) del estilismo Decó de fuentes congeladas de formas ascendentes, trasladando plenamente los valores propios de la corriente estilística, expresamente figurativa y escenográfica, cuyos parámetros, materiales y cualidades se identifican integramente en la configuración formal del Dindurra. Frank Lloyd Wright, en el Johnson Wax (1936), desarrolla una interpretación cohetánea de la imagen de fuentes congeladas de formas ascendentes, arquetípica del estilismo Decó, aprovechando los espacios residuales que los plafones entre columnas generaban en el techo para incorporar iluminación, referente argumental de la actuación proyectada en el Dindurra, resolviéndose mediante líneas quebradas, juegos de reflejos y escenografía ambiental.
\end{abstract}

\section{PALABRAS CLAVE:}

Café, Dindurra, Decó, estilo, columna.

\begin{abstract}
Architectral analysis and its historical basis were key to set the criterion argument and scope of the action developed. Contact Manuel del Busto with one of the most unique works of Hans Poelzig, the Grosses Schauspielhaus (Berlin, 1919) was established as unequivocal reference for his performance in the Dindurra (1930) the styling Deco frozen ascending forms sources, moving fully own the stylistic current expressly figurative and scenic values, whose parameters, materials and qualities are identified fully in formal settings Dindurra. Frank Lloyd Wright, the Johnson Wax (1936), develops a cohetánea interpretation of the image source frozen ascending, archetypal forms of styling Deco, taking advantage of the residual spaces that the panels between columns generated on the roof to incorporate lighting, concerning plot the projected performance in Dindurra, working by broken lines, games reflexes and environmental scenography.
\end{abstract}

\section{KEY WORDS:}

Coffee, Dindurra, Deco, style, column. 


\section{El local del Café Dindurra}

En su conjunto, el café Dindurra cuenta con total relevancia dentro de la historia de la arquitectura contemporánea asturiana por una doble razón: ser una de las obras pioneras del estilo Art-Decó en Asturias y tratarse de una intervención integral que incluye decoración y mobiliario.

Desde el punto de vista patrimonial, conviene destacar los factores que convierten a este local en una pieza única: su carácter de conjunto, su integridad, su antigüedad, su autoría, su calidad de diseño y su representatividad:

- Es una de las obras más representativas del arquitecto Manuel del Busto y Delgado.

- Actualmente, el Dindurra es el único café histórico anterior a la Guerra Civil existente en Asturias, manteniendo además su actividad en el mismo espacio físico en el que fue fundado, superando así los 115 años de actividad continuada.

- Es el interior Decó de mayor magnitud que se conserva en Gijón, tras la desaparición de los locales originales del cabaré La Gloria y el café de la sede del Real Club Astur de Regatas de la calle Corrida.

- A esto cabe añadir llevar décadas siendo un escenario esencial de la actividad social y cultural de la ciudad.

\section{Antecedentes}

El espacio ocupado por el Café Dindurra forma parte del conjunto arquitectónico levantado sobre la mitad de la manzana delimitada por las calles San Bernardo, Casimiro Velasco, paseo de Begoña y Covadonga.

Esta constituido por tres edificios promovidos por el empresario local Manuel Sánchez Dindurra (Gijón, 1859 - Madrid, 1933), diseñados con aspecto de un conjunto unitario por el arquitecto Mariano Marín Magallón en 1898. Todo ello fue erigido en el breve plazo de diez meses, incluyendo el teatro Dindurra que ocupaba la parte central de la parcela y que fue inaugurado el 28 de julio de 1899.

El complejo fue trazado siguiendo el eclecticismo en boga en el momento, si bien con la elegante sobriedad propia de Marín Magallón, aplicando una mayor elaboración compositiva y profusión decorativa en la fachada del tea- tro, atendiendo a su necesario carácter representativo.

En el proyecto inicial de 1898, el edificio que se emplaza en la confluencia del paseo con la calle Covadonga se destina a usos complementarios del teatro, emplazándose en la planta baja el vestíbulo de entrada y taquillas del mismo, junto a dos espacios destinados a café y restaurante, más tarde y hasta la actualidad, el Café Dindurra.

Manuel del Busto y Delgado, arquitecto que reformó el Dindurra en 1930 el proyecto original de Mariano Marín Magallón (1899), afecta los espacios internos y las fachadas del café, en una aproximación al modernismo.

Autor imprescindible en el paisaje urbano gijonés de la primera mitad de siglo XX, Manuel del Busto supo introducir muchos elementos del Art Decó, europeo y americano, que previamente había conocido de primera mano en sus viajes a los Estados Unidos y uno posterior a Austria y Alemania.

El contacto con una de las obras más singulares del arquitecto Hans Poelzig, el Grosses Schauspielhaus (Berlín,1919) se constituye como inequívoco referente de su actuación en el café Dindurra, trasladando plenamente los valores propios de la corriente estilística Art Decó, expresamente figurativa y escenográfica.

Las influencias del Art Decó se expresan en formas geométricas, con presencia de líneas rectas, quebradas y grecas (opuesto a las curvas sinuosas y naturalistas del Art Nouveau), el uso de la simetría y zigzags, los patrones del galón (chevrón) y el adorno en forma de sunburst, así como las imágenes de fuentes congeladas de formas ascendentes.

Correspondiendo a sus influencias maquinistas, el Art Decó se caracteriza también por los nuevos materiales: dorados, cromados, baquelita, madera embutida (taraceados), maderas nobles (caoba, ébano, palisandro) y mármoles.

Trata de representar algunas abstracciones que muestran en la naturaleza, rayos luminosos radiantes, fluidos acuáticos, nubes ondulantes... y elementos fitomorfos representados por medio de delineaciones geométricas. Utiliza imágenes de fuentes congeladas de formas ascendentes.

Todos estos parámetros y cualidades estilísticas se identifican íntegramente en la configuración formal del Dindurra.

1901-1930. El espacio actualmente ocupado por el Café Dindurra forma parte del conjunto arquitectónico levantado sobre la mitad de la manzana delimitada por las calles San Bernardo, Casimiro Velasco, Begoña y Covadonga. 


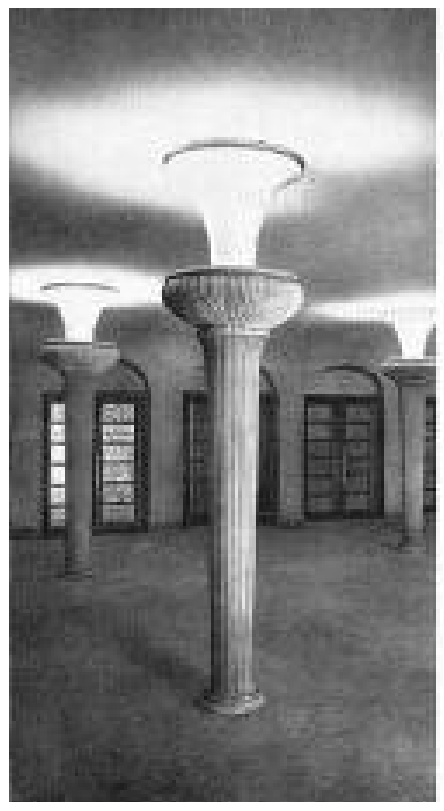

Diseño de Hans Poelzig (Grosses Schauspielhaus-1919)

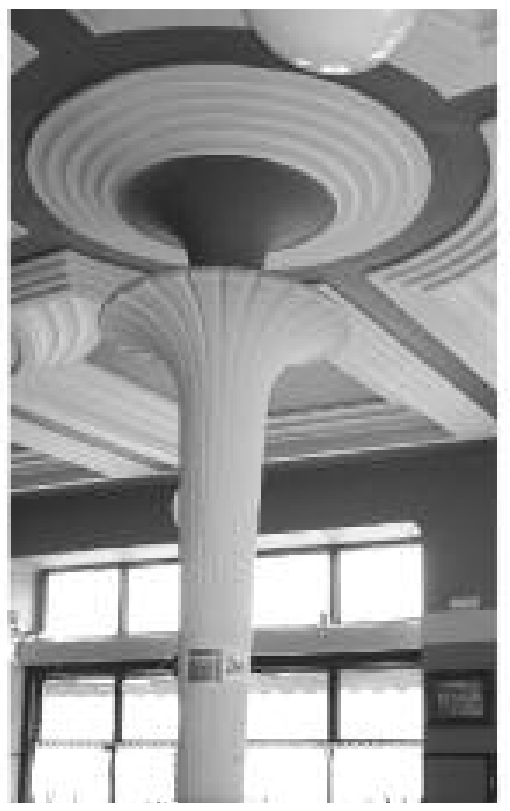

Fig. 1 Diseño de Manuel del Busto (Dindurra-1931)

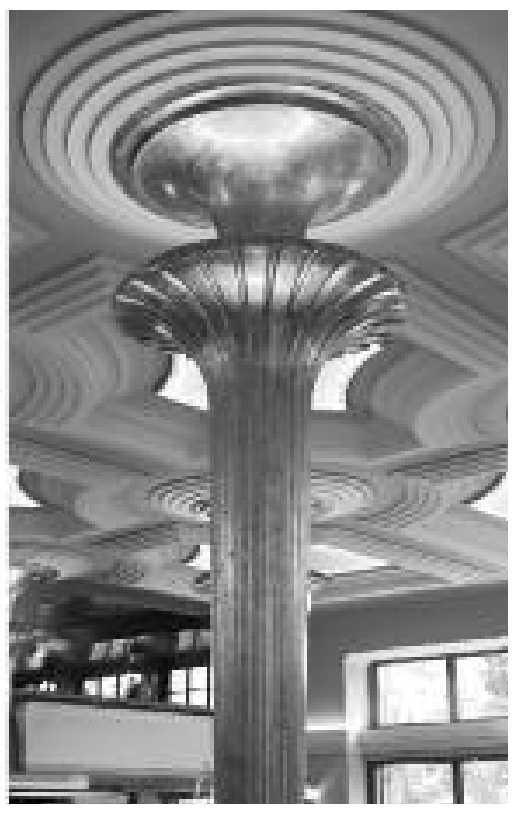

Dindurra (2014)
Está constituido por tres edificios promovidos por el empresario local Manuel Sánchez Dindurra (Gijón,1859-Madrid,1933), diseñados por el arquitecto Mariano Marín Magallón en 1898 con aspecto de conjunto unitario e incluyendo el teatro Dindurra en la parte central de la parcela.

En 1901 se independiza la actividad de este local de la del coliseo y se unifica en un espacio único para su uso como café, manteniéndose una puerta de comunicación entre ambos, ya que el café pasa también a funcionar como ambigú del teatro durante las representaciones.

Manuel Sánchez Dindurra encargó la obra de adecuación del local de nuevo a Marín Magallón, quien lo concibe siguiendo la configuración propia de los cafés decimonónicos -de hecho el aspecto final tiene gran similitud con el café Colón-: un espacio diáfano favorecido por la estructura de pilares de fundición del edificio y la altura de los techos y completado con una decoración minuciosa destacando, entre otros, una serie alegórica de los doce meses del año realizada por Alonso y Nogués, referencia a la realizada por el ilustrador checo Alphonse Mucha en 1899.

El local se amuebla con baterías de mesas de estructura metálica rectangulares con sobre de mármol y sillas tipo Thonet.

Este espacio no conoce mayores modificaciones a lo largo de las tres décadas siguientes, salvo por la incorporación de una puerta giratoria en madera de caoba cubana durante la segunda década del siglo.
1930-2013. En otoño de 1930, se encarga al arquitecto Manuel del Busto y Delgado la remodelación integral del local, obra que elimina completamente su configuración preliminar y que dota al negocio tanto de una estética vanguardista como de instalaciones con todos los servicios modernos propios del momento.

Manuel del Busto y Delgado realiza la modificación de la fachada para dotar al local de mejor iluminación y ventilación, se crea un entresuelo destinado a acoger billares y los aseos, bajo él se emplaza la barra, se diseña una nueva decoración de la sala, incluyendo su mobiliario, y se instala un sistema de calefacción centralizada.

En los años sucesivos fueron introduciéndose reformas menores y reparaciones que no alteraron la integridad del conjunto, aunque eliminaron algunas piezas de interés como los sofás de la planta baja (1965) o el aspa de la puerta giratoria (1995).

\section{Reforma y rehabilitación del Café Dindurra}

Quedando limitada la intervención sobre el local del Café Dindurra determinada por su Protección Integral del Catálogo Urbanístico de Gijón, protección que abarcaba fachadas, decoración interior y mobiliario original, se planteó la reforma y rehabilitación del local restaurando piezas existentes, recuperando las desaparecidas, y reinterpretando las características esti- 


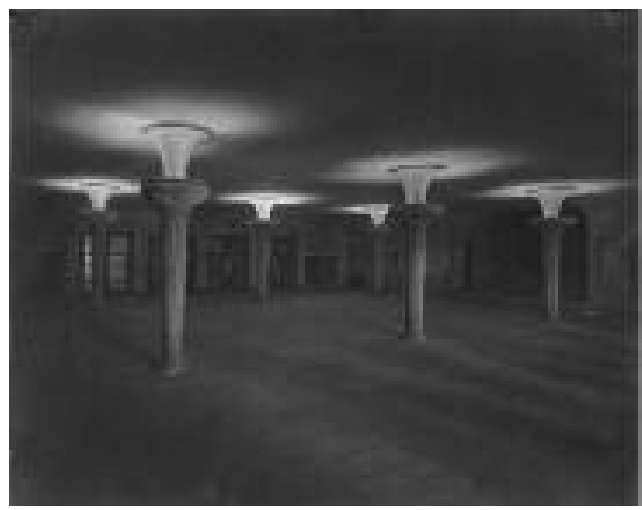

Hans Poelzig, Grosses Schauspielhaus -Berlín (1919)

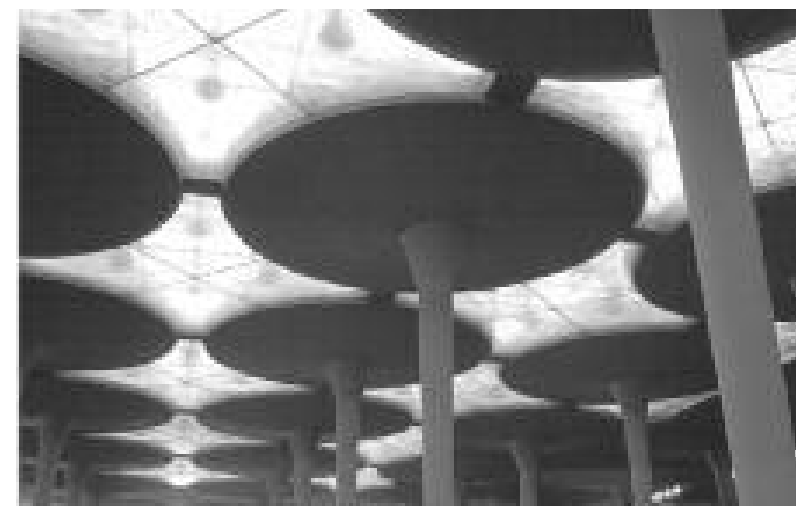

Fig. 2

Frank Lloyd Wright, edificio Johnson Wax (1936) lísticas propias del Decó, intentando regenerar la atmósfera original con su propio ambiente y estilo.

No era posible diferenciar ni disociar arquitectura de interiorismo, interiorismo de arquitectura. El Art Decó constituye un estilo globalizador, que abarcaba tanto éstas como otras muchas disciplinas y movimientos artísticos.

Durante los trabajos previos, se detectaron varias patologías constructivas y estructurales, obligando a la consolidación y rehabilitación estructural, seriamente dañada en riesgo de colapso. Significó una actuación extremadamente compleja, que supuso resolver satisfactoriamente la estabilidad y supervivencia futura del local.

Manifiestos graves daños estructurales en todas sus plantas, dimanantes de su sistema constructivo (pilares de fundición, pontones, pares y durmientes de madera), el año de ejecución (1899) y actuaciones puntuales sobre los mismos, la influencia de las diversas patologías detectadas antes de la intervención de consolidación durante la reforma del café Dindurra hubiesen provocado el colapso estructural, provocando el derrumbe del local y el propio de toda la edificación.

La más representativa se producía en los grandes asientos $(13 \mathrm{~cm}$.) de los pilares de fundición del pórtico situado en la tras-barra inicial, motivados por el apoyo de los pilares sobre vigas de madera en el techo de sótano y la afección, además, de la acción de aguas de la barra preexistente, con una importante pérdida de sección y sin cohexión de la madera, presentando una inestabilidad plena e inminente del local y el propio inmueble.

Disponiendo en planta sótano dos pilastras de ladrillo de 1 pie, entrando en carga activa con grieta diagonal viva, se dispone un empresillado perimetral armado para, toda vez encofrado, proceder a hormigonado configurando un apilastramiento reforzado. Todo ello englobando los pilares HEB-100 preexistentes del refuerzo realizado en 1978 en estructura metálica para apeo del forjado de barra y cocina. Seguidamente, se recrecieron las zapatas con idéntico criterio.

Consolidado este apartado, el hormigonado referido se realiza hasta la cara inferior de la viga de madera, al objeto de poder retirar la misma posteriormente.

La mayor complejidad radicó en cómo apear los pilares de fundición, no admitiendo soldaduras ni perforación. Se resuelve diseñando una abrazadera de iroco que reproduce el desarrollo del collarín de los pilares sobre su basa, con resaltes inferiores a $10 \mathrm{~mm}$.

Ajustado el mismo mediante barraqueros pasantes, se atornilló perimetralmente a la madera un palastro en L, al que se le suelda posteriormente un segundo collarín metálico compuesto por perfiles UPN-220 enrasados inferiormente al conformado por el palastro.

Se diseñaron unos caballetes con perfiles HEB-160, jabalconados, cuyos pies verticales apoyan en palastros recibidos sobre las pilastras de hormigón previamente ejecutadas.

Garantizada la estabilidad y ausencia de posibles deslizamientos, se secciona en partes la viga de madera inferior, se eliminan los calzos (igualmente de madera) y se retira la misma. Se completa el apoyo de los pilares de fundición ajustando en su base una carrera de tubos metálicos, procediendo a completar el hormigonado hasta la cota superior.

Se confirmó, con los testigos dispuestos, que los pilares de fundición del pórtico referido no han sufrido asiento o deslizamiento alguno durante o posteriormente a la actuación.

El minucioso análisis de la excasa documentación fotográfica existente, indujo a diseñar el 


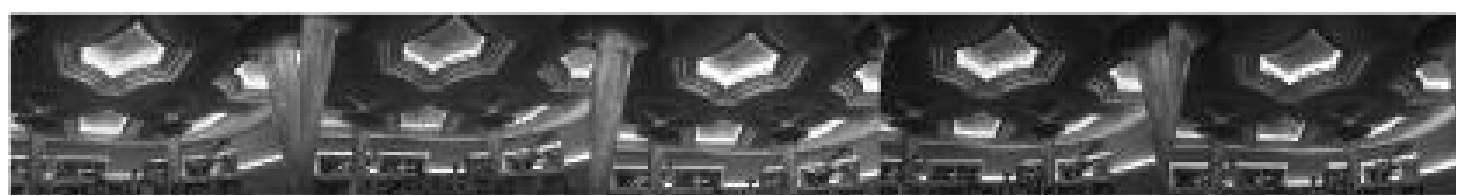

Fig. 3. Retroiluminación de casetones entre columnas

zócalo perimetral de madera y permitió descubrir aspectos desconocidos como la circunstancia que motivó el cambio de ubicación de la puerta giratoria de acceso y la del propio Teatro, tal y como hoy las conocemos, y ratificar la influencia que tuvo la actuación de Poelzig en Berlín como inspiración que influyó en Manuel del Busto para el diseño de la sala del café Dindurra:

- con motivo de la realización del altillo para billares y aseos en la reforma de Manuel del Busto en 1931, la puerta original de acceso a la cocina desde la trasbarra es desplazada (por motivos de altura) a la conexión del Café con el teatro motivando, a su vez, el reposicionamiento de la giratoria original (inicialmente en el acceso al teatro-ambigú) al actual acceso al Café desde el Paseo de Begoña

- resulta evidente la similitud de la intervención de Hans Poelzig en el Grosses Schauspielhaus en el diseño de las seis columnas presentes en la sala así como la incorporación de iluminación oculta en su parte superior. El techo se resuelve mediante una lograda composición de casetones realizados mediante molduraciones escalonadas.

Este diseño fue materializado por el escultor local José Menéndez Morán, conocido popularmente por Pepín Morán, colaborador habitual de los arquitectos Del Busto.

\section{Criterios de intervención}

El análisis histórico y su base argumental, fueron claves para establecer el criterio y alcance de la actuación finalmente desarrollada. En la intervención se tiene presente la necesidad de mantener la integridad estilística con que cuenta el local, afín al Art-Decó más arquetípico, evitando la inclusión de elementos disonantes que produzcan contrastes agresivos pero también alejándose de su redecoración mediante añadidos estilísticos miméticos que puedan falsear la imagen original del mismo.
Las columnas de la sala del Dindurra, los elementos más representativos del local, surgen del contacto de Manuel Busto con una de las obras más singulares del arquitecto Hans Poelzig, el Grosses Schauspielhaus (Berlín,1919), constituyéndose como inequívoco referente de su actuación en el café Dindurra y trasladando los valores propios de la corriente estilística Art Decó, expresamente figurativa y escenográfica.

El conjunto de la actuación, apoyándose en su proyección lumínica superior, permitió validar la interpretación de la imágen de fuente congelada de formas ascendentes, arquetípica del estilismo Decó, que Manuel del Busto incorporó del cohetáneo Hans Poelzig (Berlin-1919)

Recuperando el figurativismo y escenografía propia del Art Decó original, se determinó patinarlas en pan de oro, realizando sus basas octogonales en mármol negro y dotarlas de iluminación superior campaniforme proyectada hacia el techo y una sutil inferior desde la tabla que valora y valida su fuste estriado.

Los elementos metálicos se mantendrán latonados (dorados) y cromados (plata), y los chapados de maderas con acabados en tonos rojizos similares a la caoba y oscuros.

La luz es clave en la intervención desarrollada en el Dindurra, generando ambientes controlados y atmósferas sutiles, provocando en el café una carga subjetiva e inconsciente que confiere sensaciones a los espacios, generando emociones y validando matices propios de la escenografía Decó.

Frank Lloyd Wright, en el edificio Johnson Wax (1936), desarrolla una interpretación cohetánea de la imagen más arquetípica del estilismo Decó de fuentes congeladas de formas ascendentes, deshaciendo las cornisas y aprovechando los espacios residuales que los plafones entre las columnas generaban en el techo para incorporar la iluminación, referentes argumentales de la actuación en el Dindurra.

La iluminacion general del Dindurra se resolvió generando una iluminación oculta proyectada desde la parte superior de las columnas (Hans Poelzig, Grosses Schauspielhaus) y proyectando una retroiluminación de los casetones (Frank Lloyd Wright, edificio Johnson Wax) posibilitando el cambio cromático con- 


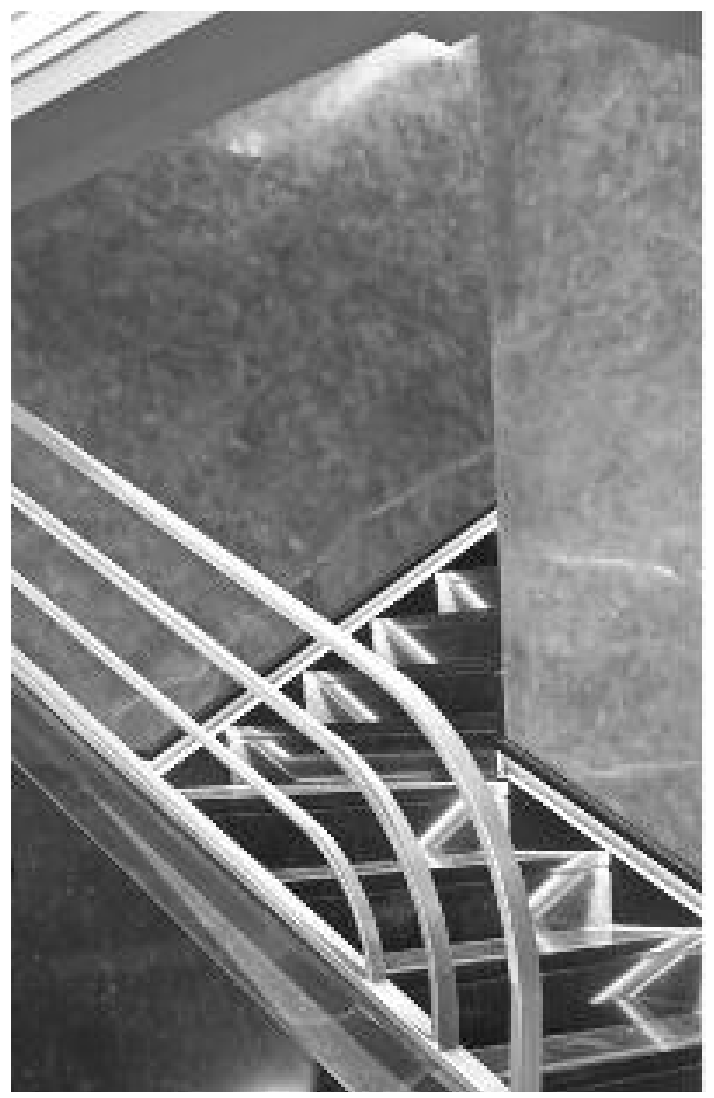

Fig. 4. Escalera proyectada. Estilismo Decó (líneas quebradas, zig-zag)

trolado de escenas en función de los diferentes ambientes, no afectando a la solución integral del conjunto y recuperando ambos referentes arquitectónicos.

Complementan la iluminación los globos y apliques de pared sobre la zocalada perimetral de madera en la Sala principal y las luminarias dispuestas sobre las bancadas de los sofás corridos. Apoyando esta escenografía, se diseña una iluminación perimetral a la sala del Dindurra, imperceptible tras incorporarla oculta en la moldura estriada que recorre todo el contorno del local y hacerla coincidir con el remate de la puerta giratoria de acceso.

La escalera original y su configuración hacia la sala principal significaba un elemento disonante dentro del conjunto general que alteraba extraordinariamente la percepción unitaria de los tres balcones del entresuelo. Se eliminaron los dos rollizos de madera que la flanqueaban, proyectando una barandilla de secciones escalonadas, acabándola en mármol negro, frontal inferior inclinado y una iluminación rasante que reproduce reflejos quebrados y zigzag, todos ellos elementos arquetípicos del Art Decó.

La barra, en pésimo estado de conservación y objeto de múltiples adaptaciones y reparacio-

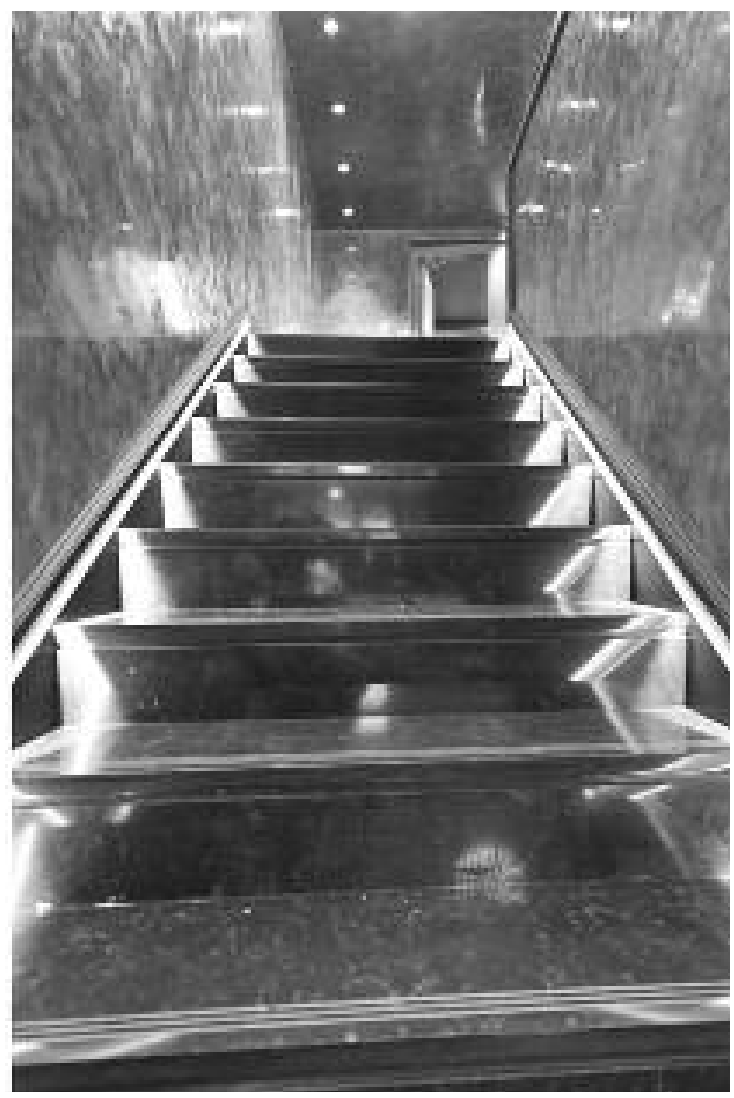

nes realizadas en su estructura y parte interna, y la necesidad de su nueva funcionalidad, hizo necesario rediseñarla manteniendo la evolución sinuosa de la original.

Se potenció el perfil escalonado Decó, acabado caoba, con meseta de mármol negro e integrando la barra-asidero, reponiendo en latón las abrazaderas existentes de acero, no originales. El reposapiés se sustituyó por uno tubular en latón, manifestando y potenciando la horizontalidad del conjunto.

De forma complementaria, se realizó el desmontaje y reinstalación (en el área central de la sala) de gran número recuperado de las piezas de baldosa hidráulica original (de la firma bilbaína Gamboa y Domingo), con diseño geométrico cuadrangular concéntrico, acompañándose de piezas nuevas de idéntico material reproduciendo el diseño geométrico y coloración de las originales, para cubrir las zonas perdidas del pavimento original.

La gama de tonos arena, ocre y marrón del pavimento determinaron la policromía general del local, posibilitando una unidad cromática integral y continua del conjunto (aspecto que perseguía la corriente estilística Decó) a la vez que fue precisa la iluminación proyectada hacia el te- 


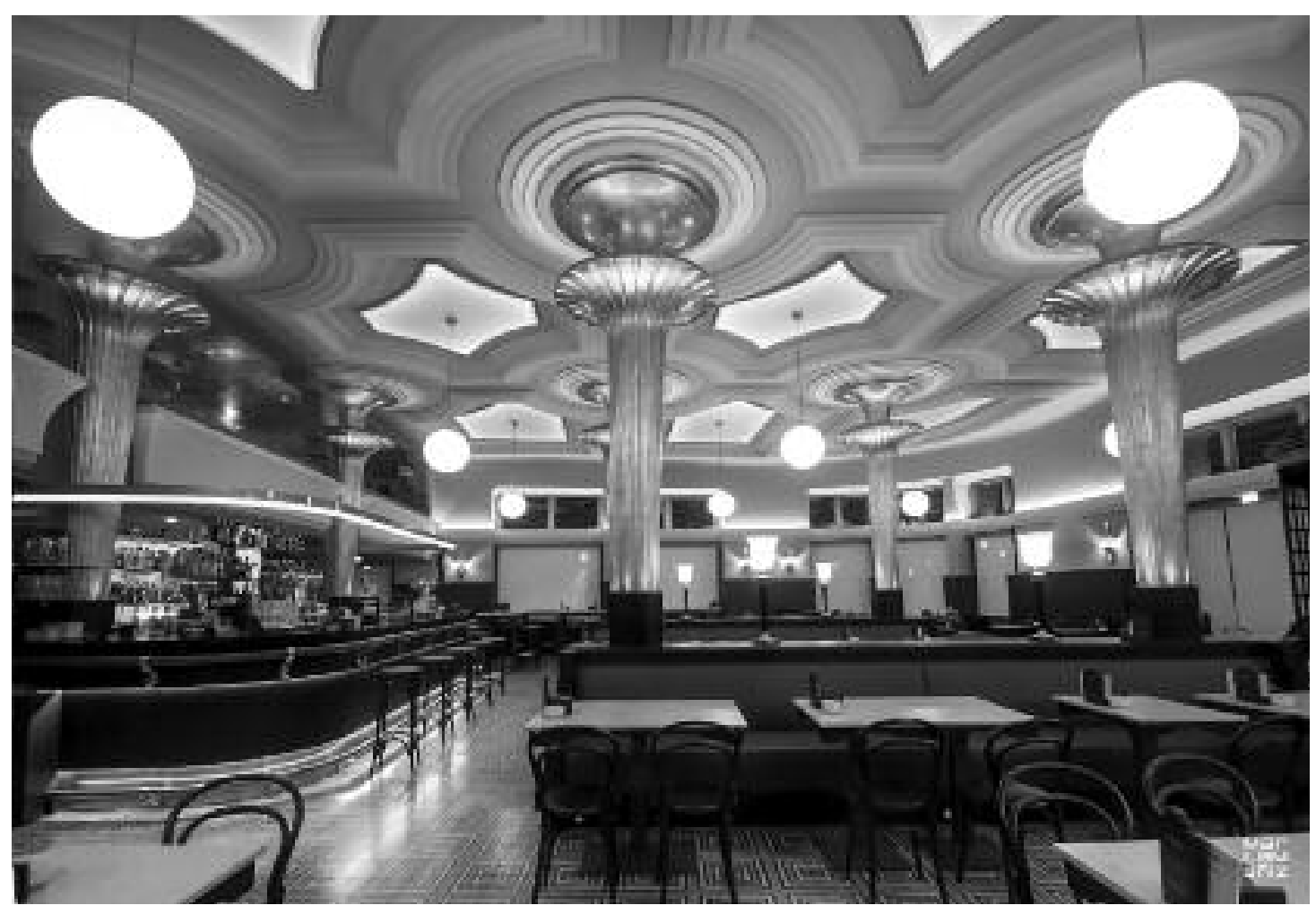

Fig. 5. Dindurra 2014

cho en las columnas como uno de los elementos originales esenciales a recuperar.

Los aseos se proyectaron siguiendo criterios propios de la arquitectura Decó más reconocible, resolviéndose mediante el dominio de las líneas quebradas y los juegos de reflejos. El interior se hace arquitectura y la arquitectura, interiorismo, simbiosis que se manifiesta durante todo el proceso de la intervención.

Se climatiza el local que, con motivo de su configuración formal y catalogación de protección integral, obligó a resolver el trazado de los conductos de impulsión y retorno mediante soluciones imperceptibles y nula afección al espacio, paramentos y volúmenes del local.

La fachada, además de dotarla de iluminación, requirió la preservación de su diseño, rehabilitando los materiales originales de los ventanales y el sistema de poleas y contrapesos metálicos, que facilita la elevación de las ventanas de guillotina, realizadas en forja labrada. Se modificó la coloración de los entrepaños significando la continuidad de los alzados del local respecto el cuerpo edificatorio del inmueble, "texturizando" sobre el paramento de la rotonda el nombre del local, Dindurra, con carácter corpóreo.

Mejorando las condiciones de evacuación y accesibilidad del local se procedió la apertura de nuevos accesos en los dos paños laterales a la puerta giratoria de acceso, manteniendo la modulación de tres huecos, disposición y formalismo de guarniciones y travesaños horizontales originales, integrando su adaptación en los criterios proyectuales originales.

Se determina la conservación y restauración del mobiliario original, los sofás perimetrales del entresuelo y las mesas realizadas en 1931, junto con las sillas tipo Thonet, así como la reproducción de un número adecuado de mesas y sillas. Puesto que las necesidades de usos actuales del espacio del café pueden requerir esponjar la distribución del mobiliario original, resulta oportuno localizar parte de las mesas y sillas comentadas en el entresuelo (donde su uso inicial como sala de billares ha desaparecido hace décadas y tampoco pretende recuperarse) y en la pared de apoyo al Teatro.

Respecto a los sofás corridos de la planta baja, hoy desaparecidos, se recuperarán partiendo de la reproducción de los originales aún presentes en el perímetro del entresuelo, puesto que los bancos corridos con cojines existentes en la planta baja constituían un elemento disonante, sin valor estético y que devaluaba la concepción original del conjunto.

Con todo, se reposicionaron los sofas originales restaurados ubicándolos en la planta baja del Café, dotándole del carácter espacial origi- 
nal y validando el propio valor patrimonial del mobiliario anteriormente desplazado, en maderas oscuras y tapizado rojo.

Se recupera la zocalada perimetral de madera en la Sala principal (boiserié) en plafonados con matices escalonados propios del Decó.

Debido a la orientación hacia el mediodía del local, parte integrante de su exterior es, desde 1901, el toldo vinculado a la fachada y en el que recayó la función complementaria de servir de rótulo comercial. No ha existido de manera uniforme un mismo tipo de grafía para dicho rótulo a lo largo del último siglo, por lo que no puede señalarse uno preferente, al igual que sucede con su coloración, entendiendo en todo caso que este elemento debería tener un fin meramente funcional sin distorsionar la imagen externa del conjunto del inmueble.
La fachada original prescinde de rótulo comercial puesto que el café, debido a su orientación hacia el mediodía, contó desde 1901 con amplios toldos que incluían el nombre del establecimiento.

Con todo ello, se disponen únicamente toldos individuales sobre los huecos de fachada, acomodando sobre el de acceso la identificación del local, disponiendo sobre el dintel de la puerta el rótulo original recuperado, pintado sobre una cuadrícula de espejos pudiendo leerse únicamente Café.

El café Dindurra evocará su memoria, su atmósfera ambiental y su escenografía emocional, escenario esencial de la actividad social y cultural de la ciudad. 